\title{
Föderalismus und Subsidiarität
}

\author{
Hrsg. v. Lars P. Feld, Ekkehard A. Köhler u. Jan Schnellenbach
}

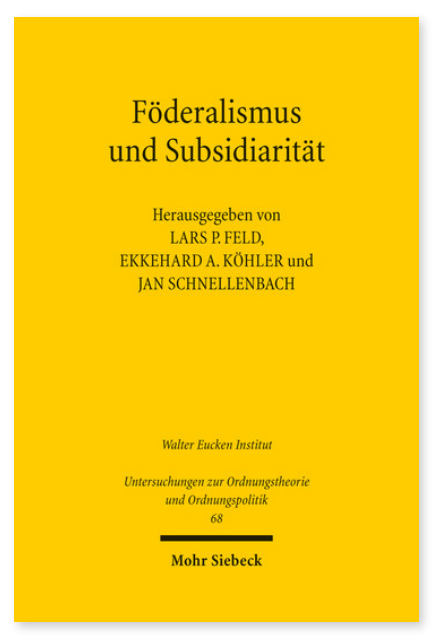

2016. XII, 199 Seiten. UOrd 68

ISBN 978-3-16-153840-7

DOI 10.1628/978-3-16-153840-7

eBook PDF $64,00 €$

ISBN 978-3-16-153839-1

fadengeheftete Broschur $64,00 €$
In diesem interdisziplinär angelegten Band werden Fragen der effizienten vertikalen Zuordnung von Kompetenzen in föderalen Systemen sowie der Möglichkeiten und Grenzen föderalen Wettbewerbs aus ökonomischer, rechts- und politikwissenschaftlicher Sicht debattiert.

Ein föderaler Staatsaufbau gilt als besonders geeignet, regionale Heterogenität in der staatlichen Ordnung zu berücksichtigen und eine Differenzierung staatlichen Handelns nach regional unterschiedlichen Bedürfnissen zu ermöglichen. Jedes föderale System aber muss die Balance zwischen dem Zentralstaat und den dezentralen Gebietskörperschaften immer wieder neu finden. Hier kommen Ökonomen, Juristen und Politikwissenschaftler zu Wort. Sie diskutieren, wie das Prinzip der Subsidiarität konkret angewendet werden kann, wie dezentrale politische Selbstbestimmung gegen die Tendenz zur Zentralisierung geschützt werden kann und welche Möglichkeiten und Grenzen es für politischen Wettbewerb in föderalen Ordnungen gibt. Dies geschieht insbesondere auch mit einem Blick auf die Europäische Union, die sich immer mehr in Richtung einer föderalen Struktur entwickelt.

Inhaltsübersicht

Vorwort

Teil 1

Subsidiarität, Selbstbestimmung und Sezession: Grundsatzfragen

Viktor J. Vanberg: Föderaler Wettbewerb, Bürgersouveränität und die zwei Rollen des Staates - Peter M. Huber: Selbstbestimmung in Europa - Roland Vaubel: Sezessionen in der Europäischen Union

Teil 2

Das Spannungsfeld zwischen Zentralisierung und Dezentralisierung in der Praxis

Hans-Günter Henneke: Gefährdungen kommunaler Selbstbestimmung: Das Beispiel Deutschland - Thomas König: Das Spannungsverhältnis zwischen Subsidiarität und europäischer Gesetzgebung - Wolf Linder: Kompetenzzuordnung und Wettbewerb im Föderalismus

Teil 3

Institutionelle Probleme föderaler Ordnungen: Globalisierung, Nation-Building und fiskalische Anreizsysteme Reiner Eichenberger/David Stadelmann: Globalisierungstauglicher Föderalismus: Elemente eines Reformprogramms Rüdiger Wolfrum: Nation- und State-Building: Gleichlaufende oder möglicherweise auch gegenläufige Prinzipien am Beispiel des Südsudan - Christoph A. Schaltegger/Marc M. Winistörfer: Insolvenzordnung für öffentlich-rechtliche Körperschaften

Lars P. Feld Geboren 1966; Studium der Volkswirtschaftslehre; 1999 Promotion; 2002 Habilitation; seit 2010 Direktor des Walter Eucken Instituts Freiburg, Inhaber des Lehrstuhls für Wirtschaftspolitik und Ordnungsökonomik an der Albert-LudwigsUniversität Freiburg und Mitglied des Sachverständigenrates zur Begutachtung der gesamtwirtschaftlichen Entwicklung.

Ekkehard A. Köhler Geboren 1979; 2006 Diplom-Volkswirt; seit 2009 Forschungsreferent am Walter Eucken Institut Freiburg; 2015 Promotion; seit 2016 geschäftsführender Forschungsreferent am Walter Eucken Institut Freiburg.

Jan Schnellenbach Geboren 1973; Studium der Wirtschaftswissenschaften; 2003 Promotion; 2009 Habilitation, venia legend für Volkswirtschaftslehre; 2012-14 geschäftsführender Forschungsreferent am Walter Eucken Institut in Freiburg; seit 2014 Professor für Volkswirtschaftslehre, insbesondere Mikroökonomik, an der BTU Cottbus-Senftenberg.

Jetzt bestellen:

https://mohrsiebeck.com/buch/foederalismus-und-subsidiaritaet-9783161538407?no_cache=1

order@mohrsiebeck.com

Telefon: +49 (0)7071-923-17

Telefax: $+49(0) 7071-51104$ 